\section{ECONOMICS}

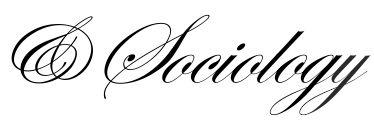

Rudminas, L., \& Baležentis, T. (2020). (Non-)Convex production metafrontier for the Baltic states. Economics and Sociology, 13(2), 228-244. doi:10.14254/2071789X.2020/13-2/15

\title{
(NON-)CONVEX PRODUCTION METAFRONTIER FOR THE BALTIC STATES
}

\author{
Linas Rudminas \\ Vilnius University, \\ Vilnius, Lithuania \\ E-mail: \\ llinas.rudminas@gmail.com
}

\section{Tomas Baležentis \\ Vilnius University, \\ Vilnius, Lithuania \\ E-mail: \\ tomas.balezentis@evaf.vu.lt}

ORCID 0000-0002-3906-1711

Received: August, 2019

1st Revision: March, 2020

Accepted: June, 2020

DOI: $10.14254 / 2071-$

789X.2020/13-2/15

JEL Classification: C44, O47

\begin{abstract}
The productive technology can be defined for different levels of aggregation (e.g., enterprises, economic sectors, economies). The groups of relatively homogenous observations can be established in order to model their performance with respect to the corresponding frontiers. The grand technology comprising all the frontiers is termed as the metafrontier. In this paper, we look into the dynamics of productivity of the three Baltic States, namely, Estonia, Latvia and Lithuania over the period of 20002016. We establish country-specific frontiers and a metafrontier in order to identify technological superiority of the countries against each other. What is more, we apply both convex and non-convex metafrontier in order to ascertain whether the underlying axioms impact the technological gaps. The results confirm the technological superiority of Estonia with regards to the other two Baltic states. Capital productivity requires improvement in Lithuania, whereas both capital and labour productivity gains are necessary in Latvia in order to approach the metafrontier.
\end{abstract}

Keywords: efficiency, productivity, metafrontier, data envelopment analysis, Baltic states

\section{Introduction}

Enterprises, economic sectors and economies may operate in different environments (as defined in the sense of infrastructure, factor endowments, geoclimatic conditions, among others). This requires certain modifications in the productivity analysis framework. One of the key underlying notions related to productivity measures is the production frontier, which, indeed, is the boundary of the technology set. Production technology and the corresponding production frontier depend on the assumptions regarding the environment of the economic entities' operation. In the context of productivity analysis, we use term decision-making units (DMUs) when referring to the entities under consideration.

To evaluate the performance (i.e., efficiency and productivity change) of the DMUs operating in a heterogeneous environment, the metafrontier approach can be exploited. For instance, O'Donnell et al. (2008) suggested using the metafrontier framework to gauge efficiencies relative to different frontiers and measuring the technology gap ratio which represents the distance between certain frontiers. Data envelopment analysis (DEA) can be used to establish the empirical production (meta-)frontier and measure the associated 
efficiency (Çalik et al., 2018; Zhang et al., 2019; Ma et al., 2019; Liu et al., 2019), including innovations as the real basic driving force for EU economies (Karnitis and Karnitis, 2017). Indeed, Charnes et al. (1981) proposed the DEA framework for measuring program and managerial efficiencies related to the metafrontier and program-specific frontier (term program refers to a certain mode of operation of the DMUs). At the country level, economies may differ in terms of infrastructure, size or structure of the labor force (O'Donnell et al., 2008).

Therefore, the metafrontier framework could be helpful for constructing technology sets allowing to account for differences among different groups of DMUs. Asmild et al. (2016) measured program efficiency of Lithuanian farms using multi-directional efficiency analysis, which allowed to evaluate efficiency measures for each input. Assaf et al. (2010) used the metafrontier framework for different groups of hotels. It allowed to compare 78 heterogeneous hotels in Taiwan by making a single homogenous technology. Lin and Hong (2019) employed metafrontier analysis for airline companies in Taiwan and China. Interestingly, Afsharian and Podinovski (2018) and Kerstens et al. (2019) noted that much research are based on constructing convex metafrontiers, e.g., O'Donnell et al. (2008). However, such a limiting assumption may lead to biased results.

The aim of this paper is to apply the metafrontier framework for analyzing efficiency differences in the three Baltic States (Estonia, Latvia and Lithuania) by means of DEA. Given the observations above, we apply convex and non-convex specifications of the metafrontier. We apply the EU KLEMS database for 2000-2016. The empirical example is interesting in several regards. First, the three Baltic States are located in a compact region, yet there are certain differences among them in terms of economic development. Second, all three countries are the new EU Member States undergoing economic transformations. Third, they were affected by the economic crisis of 2008 which is included in the period covered.

The paper unfolds as follows. Section 1 presents the literature review. The measures of efficiency along with the relevant DEA models are discussed in Section 2. Section 3 discusses the data used. The results are presented in Section 4.

\section{Literature review}

The concept of the metafrontier has been applied in the economic analysis spanning over different regions, sectors and levels of aggregation. This section presents a brief overview on the examples of the metafrontier in efficiency and productivity analysis. These studies applied the DEA as an estimator of the efficiency (with some exceptions).

Beltrán-Esteve et al. (2019) analysed the performance of the European Union countries with regards to both economic and environmental performance. The Luenberger productivity indicator was applied in the metafrontier setting. The two groups of the countries were considered (the new and old EU Member States). The inputs included capital stock and labour force. The gross domestic product was considered as a desirable output. The environmental pollution was included into the modelling by considering the undesirable outputs.

Chang (2019) also considered the case of the EU and defined the two groups of countries: those belonging to the Baltic Sea Region and the remaining ones. The inputs included capital stock, labour force and energy consumption. The desirable output was the real gross domestic product and the carbon dioxide emission was included as an undesirable output.

Chang and $\mathrm{Hu}$ (2019) looked into efficiency of the G7 and BRICS countries. Therefore, the two group frontiers were established. The inputs included capital stock, labour 
force and energy consumption. The desirable and undesirable outputs were the gross domestic product and carbon dioxide emission, respectively.

Chiu et al. (2019) applied the Stochastic Frontier Analysis to measure the efficiency of the Indonesian, Vietnamese and Chinese enterprises. In this case, the countries corresponded to groups. The output was the production volume in electronics and textile industry. Inputs included the number of employees, fixed capital stock and intermediate inputs.

Ding et al. (2019) analysed the performance of the Chinese cities belonging to different urban agglomerations. The urban agglomerations were considered as the groups (184 cities were divided into 12 agglomerations). The productive technology included three inputs (labour force, capital stock and land area), one desirable output (gross domestic product) and two undesirable outputs (sulfur dioxide emission and industrial fumes).

Zha et al. (2020) applied the non-convex meta-frontier to measure the performance of the tourism industry in China. The provinces were classified into the three regions (eastern, central, western) and the corresponding frontier were established. The tourism performance was measured in terms of the four inputs (employees, capital stock, tourism resources, energy consumption), a desirable output (revenue) and an undesirable output (carbon emission).

Wang et al. (2019) assessed the efficiency of the power plants in China. The two groups of the power plants were considered: state and private ones. The inputs included installed capacity, energy consumption and labour force. The outputs included electricity production and carbon dioxide emission as the desirable and undesirable outputs, respectively.

Chen et al. (2020) used the cross-efficiency DEA to measure the transportation efficiency of China's provinces. The provinces were grouped into regions. The technology included three inputs (employees, capital stock and energy consumption) along with a desirable output (gross regional product) and an undesirable one (carbon dioxide emission).

Kounetas and Zervopoulos (2019) assessed the performance of the 103 countries by grouping them into Annex I and non-Annex I countries according to the Kyoto protocol. In this instance, the inputs included capital stock, labour force and energy consumption. The desirable out was gross value added, whereas the undesirable one was the carbon dioxide emission.

\section{Methodological approach}

This section presents the key blocks for assessment of the technical efficiency of the three Baltic States. First, we present the concepts of technology and efficiency. Then, we focus on the notion of the metafrontier. Finally, the DEA estimators are presented.

\subsection{Technology set and efficiency}

This section follows the literature on the frontier measures of efficiency and productivity (Latruffe, 2010; Daraio \& Simar, 2007). The pioneering works in the area are studies by Koopmans (1951) and Debreu (1951) along with empirical models offered by Farrell (1957). In its essence, efficiency measures the ratio of the observed productivity to the maximal possible one ${ }^{1}$. The maximal productivity is obtained by considering the projection of the production frontier. As one often has multiple inputs and/or output in the technology, the notion of the total factor productivity becomes important. Basically, one needs to aggregate multiple variables into aggregate inputs and outputs in order to compute the total factor

\footnotetext{
${ }^{1}$ Note that the exact specification of the ratios mentioned in this paragraph depend on the type of the efficiency measure used in the analysis. Anyway, the same variables are used independently of the efficiency measures.
} 
productivity. In case a radial movement is assumed (i.e. only input or output vector is scaled), efficiency boils down to the ratio of the observed output quantity to the potential one (input quantities are analyzed in case of the input-orientation).

The production technology is defined in terms of the production possibility set. The set comprises input and output quantities arranged in the form of vectors. Thus, the technology is defined as the following set (O'Donnell et al., 2008):

$T=\{(x, y): x$ can produce $y\}$.

The technology can be represented in terms of primal or dual representations. These representations satisfy certain economic axioms, see, e.g. Färe and Primont (1995). As one of the primal representations, the output correspondence sets related the given level of inputs to the possible values (quantities) of the outputs:

$$
O(x)=\{y:(x, y) \in T\} \text {. }
$$

The distance to the production frontier can be gauged by considering the measures of efficiency. Farrell efficiency measure and Shephard distance function are the basic measures representing the radial movement in the input or output space. The output distance function (Shephard, 1970) is defined as follows:

$$
\left.D_{O}(x, y)=D>0:\left(\frac{y}{D}\right) \in O(x)\right\} \text {. }
$$

Indeed, Eq. 3 defines the maximum possible expansion of the output vector keeping its structure fixed. The value of unity indicates technical efficiency, whereas values below unity indicate inefficiency.

\subsection{Metafrontier approach}

Assuming that the DMUs face different operation environments, we establish index $s=1,2, \ldots, S$ for the group technologies. Therefore, a certain DMU belongs to a group technology and the meta-technology. Accordingly, efficiency (or distance to the frontier) can be measured for the group technology and meta-technology. The difference between these two measures is the technological gap or distance between the frontiers.

Formally, group technology can be defined in terms of the input and output vectors:

$T^{s}=\{(x, y): x$ can be used by firms in group $s$ to produce $y\}$.

Similarly, the output correspondence sets and Shephard distance functions can be defined relative to the group technologies:

$$
\begin{aligned}
& O^{s}(x)=\left\{y:(x, y) \in T^{s}\right\}, s=1,2, \ldots, S \\
& \left.D_{O}^{S}(x, y)=D>0:\left(\frac{y}{D}\right) \in O^{s}(x)\right\}, s=1,2, \ldots, S .
\end{aligned}
$$

The metafrontier, $T^{c}$, is then defined in terms of the group frontiers. The convex metafrontier is obtained as follows (Pastor, Lovell, 2005):

$$
T^{C}=\operatorname{Conv}\left(T^{1} \cup T^{2} \cup \ldots \cup T^{S}\right) \text {, }
$$

where $\operatorname{Conv}($.$) denotes a convex envelope. As it was outlined in Introduction, one may prefer$ to model a non-convex metafrontier. In the latter instance, the metatechnology is defined as a union of the group technologies (Kerstens et al., 2019):

$T^{N C}=T^{1} \cup T^{2} \cup \ldots \cup T^{S}$.

Let $T^{\prime}$ denote a metatechnology, where $T^{\prime}=\left\{T^{C}, T^{N C}\right\}$. Formally, the dependence of a certain observation the technologies defined in Eqs. 4,7 and 8 is characterized by the following rules (O'Donnell et al., 2008):

Rule 1. If $(x, y) \in T^{s}$ for any $s$ then $(x, y) \in T^{\prime}$;

Rule 2. If $(x, y) \in T^{\prime}$, then $(x, y) \in T^{s}$ for some $s$;

Rule 3. $D_{O}^{S}(x, y) \geq D_{O}(x, y)$ for all $k=1,2, \ldots, K$. 
Given the group frontiers and the metafrontier can be either convex or non-convex, the following rules is established (O'Donnell et al., 2008):

Rule 4. Convex $O(x)$ does not necessarily imply convex group output sets, $O^{s}(x), s=$ $1,2, \ldots, S$; and vice versa.

Fig. 1 presents a graphical interpretation of the group and metafrontier. Specifically, point $A$ denotes a certain production plan belonging to group technology spanned by frontier $T^{1}$. The metafrontier can be defined by assuming convexity or non-convexity with projections at points $D$ and $C$ respectively.

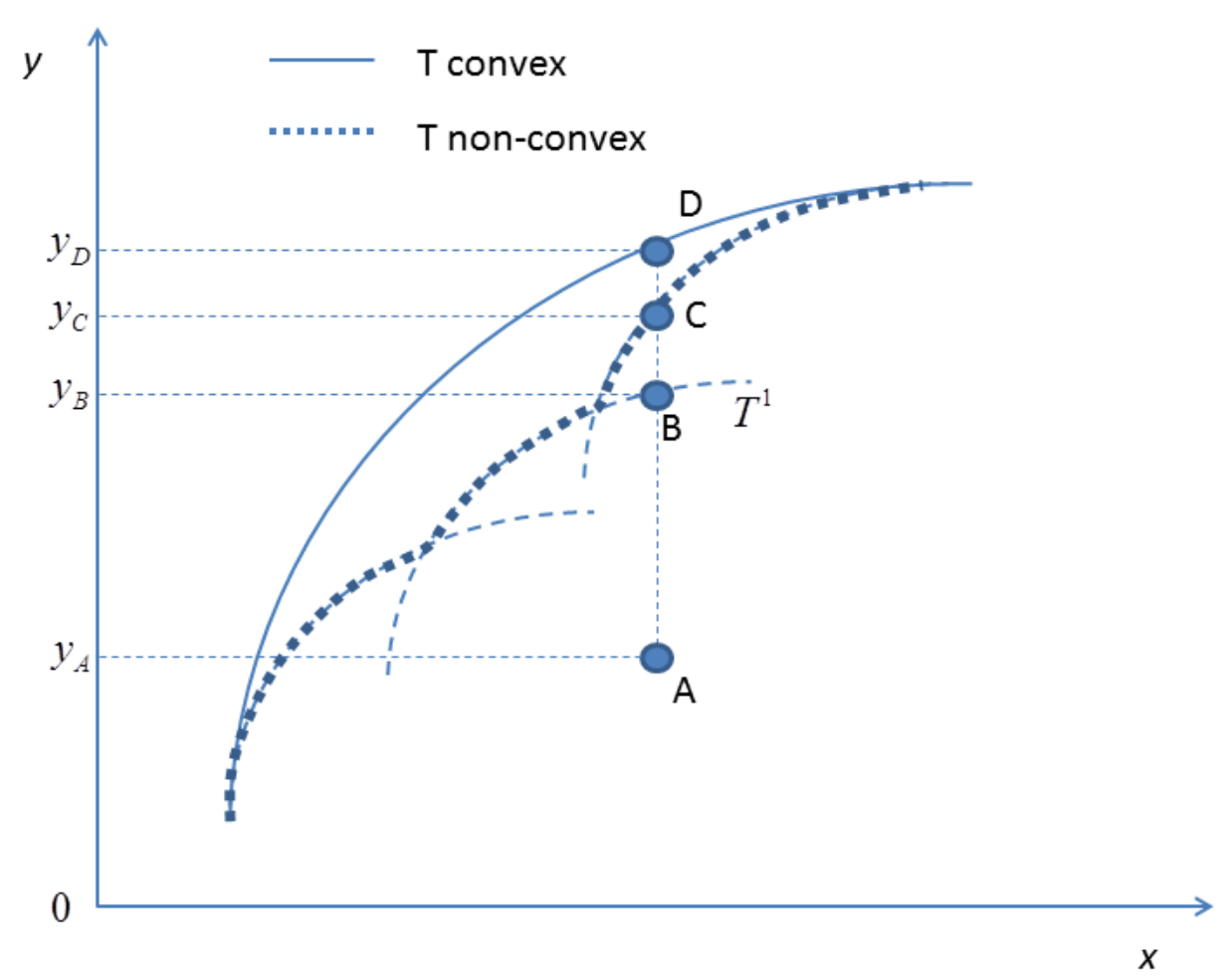

Figure 1. Technical efficiency and metatechnology

Source: designed by the authors.

Managerial output-oriented technical efficiency for production plan A (Fig. 1), $D_{O}^{1}\left(x_{A}, y_{A}\right)$, is defined as the ratio $0 y_{A} / 0 y_{B}$. The projection on the convex metafrontier is associated with efficiency score defined by $D_{O}^{C}\left(x_{A}, y_{A}\right)=0 y_{A} / 0 y_{D}$. Similarly, projection on the non-convex metafrontier is associated with $D_{O}^{N C}\left(x_{A}, y_{A}\right)=0 y_{A} / 0 y_{C}$.

Besides managerial technical efficiency measured against the group frontier, one can also measure the group efficiency. The group efficiency (or program efficiency) indicates performance of observations on the group frontier if compared to the metafrontier. This allows identifying the differences in the production potential existing across different group technologies (and group frontiers). The difference between a group frontier and the metafrontier is measured by the technology gap ratio (or metatechnology ratio). Let $D_{o}(x, y)$ be the distance relative to the metafrontier and $D^{s}(x, y)$ be the distance relative to the group frontier. Then, technology gap ratio for observation in group $s$ is measured as (O'Donnell et al., 2008):

$$
\operatorname{TGR}^{s}(x, y)=\frac{D(x, y)}{D^{s}(x, y)}
$$


Obviously, the distance to the metafrontier decomposes as

$$
D(x, y)=T G R^{s}(x, y) D^{s}(x, y) \text {. }
$$

As we consider both convex and non-convex metafrontier, the technology gap ratio can be established with respect to each of these. In that case, the numerator on the right hand side of Eq. 9 is replaced with $D_{O}^{C}(x, y)$ or $D_{O}^{N C}(x, y)$.

\section{3. $\mathrm{DEA}$}

The measures of efficiency defined in the preceding sub-sections require empirical estimators. In this paper, we embark on the non-parametric technique, namely DEA. Farrell (1957) developed the programming model for DEA with subsequent formulations by Charnes, Cooper and Rhodes (1978) and Banker, Charnes and Cooper (1984). The latter study adopted the variable returns to scale technology.

The DEA relies on a piece-wise linear approximation of the production frontier. The linear combinations of inputs and outputs are used to construct the technology. Assuming free disposability, convexity and constant returns to scale (Bogetoft \& Otto, 2011) the empirical technology set is established:

$$
T=\left\{(x, y) \mid x \geq \sum_{k=1}^{K} \lambda^{k} x^{k}, y \leq \sum_{k=1}^{K} \lambda^{k} y^{k}, \lambda^{k} \geq 0, k=1,2, \ldots, K\right\},
$$

where $\lambda$ is the weight vector and $k=1,2, \ldots, K$ is the index of DMUs. The resulting technology set is a convex cone.

The DEA can be applied to measure the distance between a certain observation $\left(x^{t}, y^{t}\right)$ and the production frontier. Furthermore, let $i=1,2, \ldots, m$ and $j=1,2, \ldots, n$ be the indexes for inputs and outputs respectively. Then, the output-oriented constant returns to scale envelopment DEA model (Bogetoft, Otto, 2011) takes the following form:

$$
\begin{aligned}
& 1 / D_{O}\left(x^{t}, y^{t}\right)=\max _{\phi_{t}, \lambda_{k}} \phi_{t} \\
& \text { s.t. } \\
& \sum_{k=1}^{K} \lambda_{k} x_{i}^{k} \leq x_{i}^{t}, i=1,2, \ldots, m ; \\
& \sum_{k=1}^{K} \lambda_{k} y_{j}^{k} \geq \phi_{t} y_{j}^{t}, j=1,2, \ldots, n ; \\
& \lambda_{k} \geq 0, k=1,2, \ldots, K .
\end{aligned}
$$

In order to calculate the efficiency scores for group technologies and metatechnology, the left hand side of the constraints in Eq. 12 is modified. Specifically, the measures relative to the group frontier are obtained by including group observations in the reference technology given in the left hand side of constraints in Eq. 12. As for the metatechnology, the two options are available. For the convex metatechnology, the left hand side of the constraints include all the observations (i.e. all the groups are included). As for the non-convex metatechnology, the DEA model is implemented for each group technology acting as a reference technology. Thereafter, the maximum value of the obtained efficiency measures serves as the global efficiency scores:

$$
\frac{1}{D_{O}^{N C}}=\max _{S=1,2, \ldots, S} \frac{1}{D_{O}^{s}}
$$

Each linear programming problem has its dual specification. For the DEA model, the multiplier model is available (Ramanathan, 2003). The weights used in the multiplier model correspond to the marginal products of the input variables. Thus, we use them to identify the contributions of the input variables towards the aggregate input. 


\section{Data used}

The databases for macro-level research include World Input-Output Database (Timmer et al., 2015) and EU KLEMS database (Jäger, 2017) among others. In our case, the EU KLEMS database was chosen as a data source. This database contains data on capital and labor stocks which serve as inputs in the analysis. EU KLEMS database contains the data for the three Baltic States. The annual data for 2000-2016 are used. Because the data will be compared among the years, the real values of inputs and outputs will be analyzed.

The choice of inputs and outputs is in line with similar research (Giraleas et al., 2012). The two-inputs and one output are included in the analysis. Asa regards the inputs, capital stock and labor input are included. To represent the capital input, the real fixed capital stock in 2010 prices is chosen (measured in Euro). Total hours worked by employees is used as the labor input. The output indicator is the Value Added measured at current basic prices and adjusted by the price indices (base year 2010). Thus, monetary variables are deflated in order to allow for meaningful comparisons over time. The inputs and outputs are analyzed at the country level. Table 1 presents the descriptive statistics.

Table 1. Descriptive statistics of the input and output variables

\begin{tabular}{|c|c|c|c|c|c|}
\hline Variable & $\begin{array}{l}\text { No. of } \\
\text { obs. }\end{array}$ & Mean & SD & Min. & Max. \\
\hline \multicolumn{6}{|c|}{ Estonia } \\
\hline Capital (million Eur of 2010) & 17 & 39950 & 10520 & 22967 & 54240 \\
\hline Labor (hours) & 17 & 1056137 & 53036 & 971763 & 1162560 \\
\hline $\begin{array}{l}\text { Value Added (million Eur of } \\
\text { 2010) }\end{array}$ & 17 & 13153 & 2062 & 9249 & 15779 \\
\hline \multicolumn{6}{|c|}{ Latvia } \\
\hline Capital (million Eur of 2010) & 17 & 83034 & 3768 & 77619 & 87611 \\
\hline Labor (hours) & 17 & 1570849 & 119159 & 1434450 & 1877651 \\
\hline $\begin{array}{l}\text { Value Added (million Eur of } \\
\text { 2010) }\end{array}$ & 17 & 16165 & 2757 & 10737 & 19388 \\
\hline \multicolumn{6}{|c|}{ Lithuania } \\
\hline Capital (million Eur of 2010) & 17 & 80236 & 11214 & 63031 & 96056 \\
\hline Labor (hours) & 17 & 2149333 & 114700 & 1980730 & 2422249 \\
\hline $\begin{array}{l}\text { Value Added (million Eur of } \\
\text { 2010) }\end{array}$ & 17 & 25102 & 4585 & 16479 & 31059 \\
\hline
\end{tabular}

Source: designed by the authors using the EU KLEMS database (Jäger, 2017; Stehrer et al., 2019)

\section{Results}

In this section, the macroeconomic performance of the three Baltic States - Estonia, Lithuania and Latvia - is analyzed. Specifically, we apply the DEA to the dataset described in Section 2 to (i) assess the dynamics in the productivity of separate countries and (ii) identify the differences in the production possibilities possibly existing among these countries. First, we focus on the country-level analysis and identify the changes in efficiency (productivity) along with the contributions of the inputs towards the output generation (i.e., we analyse the marginal products). Second, the convex and non-convex metafrontiers are constructed to compare the country-specific technologies among themselves. The technology gap ratios based on the two instances of the metafrontiers are calculated. 


\subsection{Country-level analysis}

We begin our analysis with estimation of the country frontiers. The DEA is implemented by applying the Benchmarking package (Bogetoft \& Otto, 2011) in R. As the output-oriented DEA CRS model is applied, we use the Shephard output distance function (Eq. 2) efficiency scores to ensure interpretability. The efficiency scores equal to 1 indicate full efficiency and the lower values correspond to the output gap. Fig. 2 presents the efficiency scores for the three Baltic States from 2000 to 2016.

A more general description of the efficiency scores can be obtained by considering the descriptive statistics which are further presented in Table 2. By construction, the maximum values of the efficiency scores are equal to unity across all the countries. The minimum efficiency scores take the lowest value in Latvia, whereas Estonia has the highest value. The mean values follow the same order. The countries are ranked in the opposite manner if the standard variation is considered, i.e., Estonia shows the highest level of efficiency along with the lowest variation. In general, the efficiency levels observed for the three Baltic States are rather high.

Table 2. Descriptive statistics of the efficiency scores for each country

\begin{tabular}{lcccc}
\hline \multicolumn{1}{c}{ Country } & Mean & Minimum & Maximum & SD \\
\hline EST & 0.9613 & 0.8564 & 1 & 0.0385 \\
\hline LTU & 0.9196 & 0.7450 & 1 & 0.0803 \\
\hline LVA & 0.8647 & 0.6122 & 1 & 0.1208 \\
\hline
\end{tabular}

Source: designed by the authors.

Obviously, Estonia exploits its production factors to the highest extent (relative to its own production frontier) if opposed to the other countries considered. Indeed, the full efficiency is maintained for years 2006, 2007, and 2016. In these years, the Estonian economy operated efficiently, i.e., it was able to produce its maximum output at the given input level. Fig. 2 suggests that the country experienced a sharp decrease in efficiency during 2008 and 2009, which could be attributed to the financial crisis. Afterwards, Estonia recovered at the highest rate (or dominated by Lithuania) among the three countries considered and maintained the optimal output level again in year 2016.

Turning to Lithuania, its efficiency scores raised quite smoothly till the year 2008 . Note that Lithuania and Latvia show an increasing efficiency, whereas Estonia is fluctuating during 2000-2008. The economic crisis affected the technical efficiency. Year 2009 marked an extremely steep decrease in efficiency. Afterwards, the Lithuanian economy kept recovering till year 2014 when the efficiency frontier was achieved again. Afterwards, the efficiency remained extremely high, yet th economy departed from the efficiency frontier.

In the case of Latvia, the growth in efficiency was observed until year 2007, when full efficiency was achieved. Indeed, Latvia started from the lowest efficiency level indicating that the production capacity was underexploited in 2000 . In year 2008, the efficiency decreased due to the financial crisis. The sharp decrease in efficiency during 2008-2009 was accompanied with a recovery during 2009-2016 with full efficiency in 2016.

There can be certain patterns observed for the efficiency scores. In general, Lithuania and Latvia follow similar trends in this regard prior to the economic crisis. Estonia remained at higher efficiency levels in most cases and showed lower degree of volatility in the technical efficiency scores (considering deviations from the underlying trend). The distinction between Lithuania and Latvia on the one side and Estonia on the other can be explained by the different directions and degrees of economic integration of these countries. Indeed, Estonia is 
more integrated in the economic system of the Nordic countries. What is more, Estonia was less affected by the global economic crisis possibly due to the fact that Estonia's government took precautionary measures while the two other Baltic States remained optimistic (Purfield \& Rosenberg, 2010; Kattel \& Raudla, 2013).

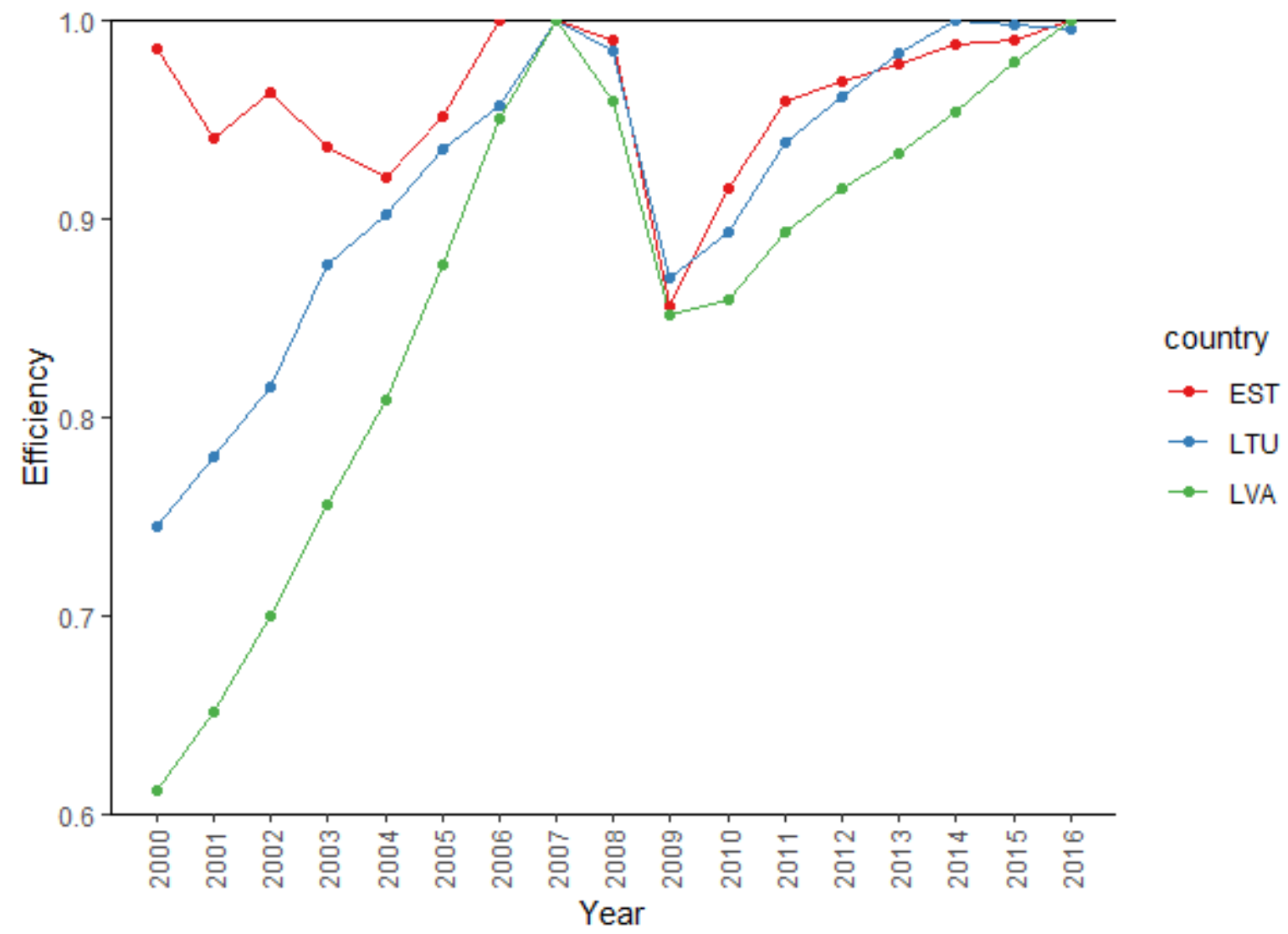

Figure 2. The output-oriented efficiency scores for the Baltic States

Source: designed by the authors.

The DEA relies on the linear programming which can be carried out following the principle of duality. Therefore, the envelopment program in Eq. 12 can be translated into the multiplier model (see, e.g., Bogetoft \& Otto, 2011). The multipliers of the multiplier DEA model indicate the contributions (marginal products) of the inputs towards generation of the outputs. In this paper, we consider the marginal products of the inputs multiplied by the input quantities and normalized by the sum of these products. As a result, we obtain the relative contributions of the inputs presented in Fig. 3.

Looking at the results for Estonia, one can note that there has been a gradual transition from capital-oriented economic growth to labour-oriented one. In the former case, capital is the limiting factor, i.e., the increase in the capital inputs renders higher increase in output than it is the case for labour. The share of capital dominated the output generation during 20002006. Afterwards, labour became the limiting factor of the economic growth. The same results were obtained earlier for the whole EU, not only for the Baltic States (Bilan et al., 2020).

A similar pattern can be observed for the cases of Lithuania and Latvia. However, labour became more important there over time, yet it did not significantly offset the share of the capital input until 2010 there. The increasing importance of the labour input can be related to the declining labour supply and the improving quality of the human capital. Therefore, 
further economic growth in the Baltic States definitely requires more attention towards the labour force and its quality. As the results suggests, Estonia faced the increasing marginal productivity of labour earlier than the other Baltic States did. Therefore, Estonia can be regarded as a more advanced economy with higher labour productivity which corresponds to situation in the Nordic countries.

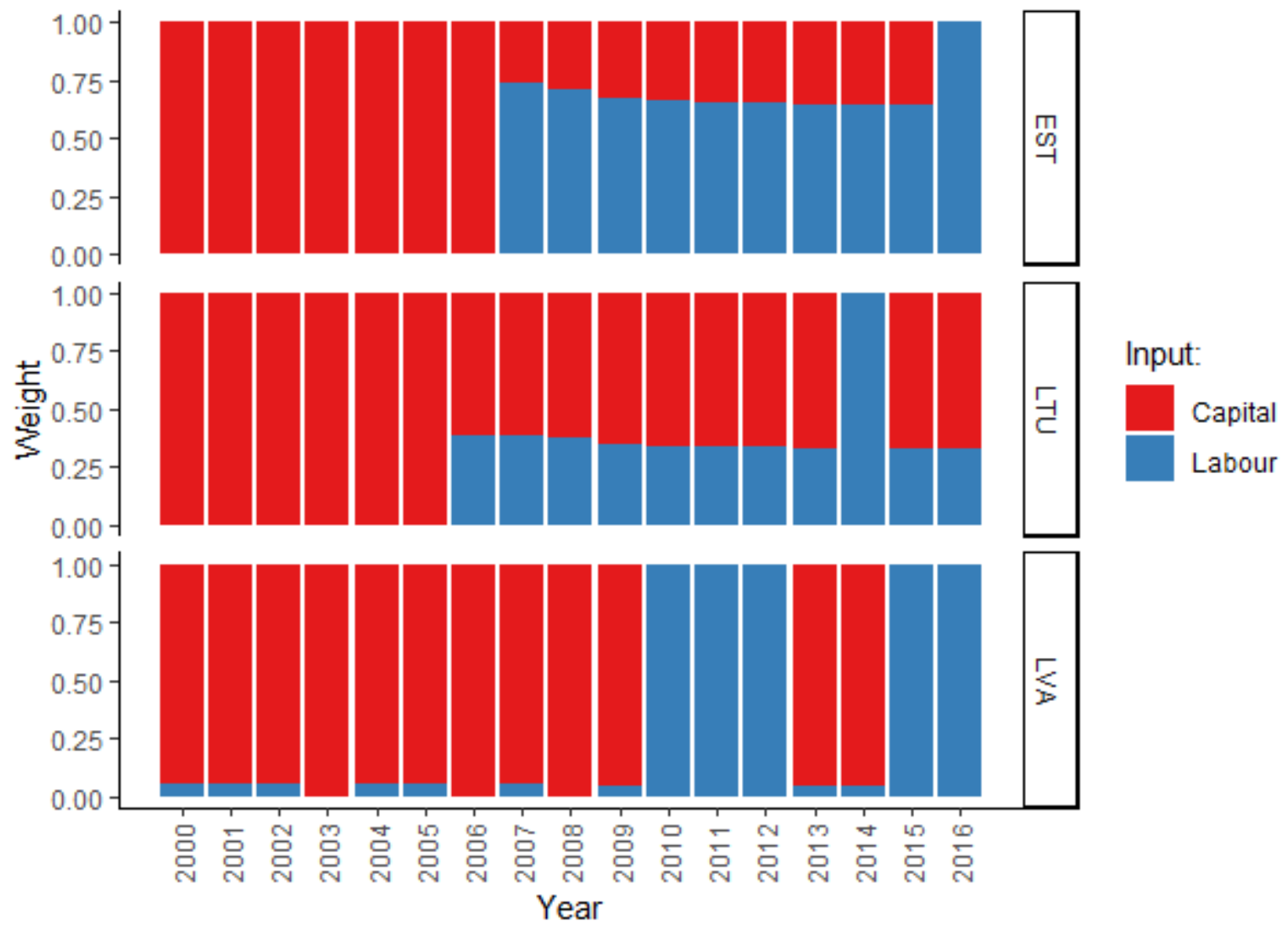

Figure 3. The relative contributions of inputs to the output production Source: designed by the authors.

The nature of DEA implies that the weak efficiency may be observed for certain data points as they are located on the parts of the piece-wise production function parallel to the coordinate axes. This indicates that the output production can be maintained by using lower quantities of the inputs or that more output could be generated for the same quantity of inputs. This renders zero multipliers associated with certain inputs. As we can see, Fig. 3 contains several such cases. The problem of zero weights can be circumvented by applying improved DEA models with, e.g., weight restrictions or assurance regions. Such approaches may increase the discriminatory power of the DEA model yet they require arbitrary choice of the parameters for the restrictions on the multipliers. In our case, we seek to provide the stylized facts about the economies of the Baltic States without extensive discussion on the formation of the output from the viewpoint of the DEA-based production frontier. An interested reader may consult Joro and Korhonen (2015), Podinovski (2016), Liu et al. (2013) for the DEA models with weight restrictions. 


\subsection{Metafrontier analysis}

The inter-country comparison of the production possibilities is further facilitated by constructing the metafrontier. We embark on constructing two instances of the metafrontier a convex one and a nonconvex one. Table 3 shows the descriptive statistics of the efficiency scores obtained under each approach. Again, we follow the definition of the Shephard output distance function, where the full efficiency is indicated by the value of unity and the lower values imply the presence of inefficiency. These efficiency scores compare the performance of a certain country to the best possible practice in the Baltic States' region.

Table 3. Descriptive statistics of the efficiency scores relative to the convex and nonconvex metafrontiers

\begin{tabular}{|c|c|c|c|c|}
\hline Country & Minimum & Maximum & Mean & SD \\
\hline \multicolumn{5}{|c|}{ Convex metafrontier } \\
\hline EST & 0.8564 & 1.0000 & 0.9613 & 0.0385 \\
\hline LTU & 0.6421 & 0.9924 & 0.8621 & 0.1085 \\
\hline LVA & 0.4687 & 0.8622 & 0.6949 & 0.1216 \\
\hline \multicolumn{5}{|c|}{ Non-convex metafrontier } \\
\hline EST & 0.8564 & 1.0000 & 0.9613 & 0.0385 \\
\hline LTU & 0.6421 & 0.9924 & 0.8621 & 0.1085 \\
\hline LVA & 0.4687 & 0.8622 & 0.6949 & 0.1216 \\
\hline
\end{tabular}

Source: designed by the authors.

When the meta-technology is used as a reference, the lowest efficiency score is obtained for Latvia (i.e., the lowest minimum value among the three countries). In this case, the observed output quantity constitutes only $47 \%$ of the output quantity observed on the convex metafrontier. The same conclusion can be obtained by looking at the average values. The average efficiency score (compared to the metafrontier) for Latvia is 0.69. Latvia did not manage do approach the metafrontier as the maximum efficiency score (measured against the meta-frontier) is 0.86. Lithuania show the maximum score of 0.99 . Therefore, the metafrontier is constructed by Estonia.

The results are not different across the convex and non-convex settings. This is induced by the dominance of Estonia in the meta-frontier. As the technology for the Estonian economy dominates the technologies for Lithuania and Latvia, the technology gap ratio (TGR) defined by Eq. 9 is not variant across the convex and non-convex meta-frontiers. It measures the gap between a country-specific frontier and the metafrontier in our case. The resulting measures are summarized in Table 4. Taking Latvia as an example, the TGR of 0.8 implies that the Latvian production frontier corresponds to the $80 \%$ of the output obtained by exploiting the same quantities of the inputs in the Baltic States as suggested by the metafrontier. As Estonia acts as the only benchmark in the meta-technology, the comparison is made to the Estonian economy. The average TGR for Lithuania is 0.93. This implies that the Lithuanian production frontier is close to the metafrontier for the Baltic States. Estonia shows the highest TGR implying zero distance between the country-specific frontier and the metafrontier. 
Table 4. Descriptive statistics of the technical gap ratio (TGR) for convex and non-convex metafrontiers

\begin{tabular}{|c|c|c|c|c|}
\hline Country & Minimum & Maximum & Mean & SD \\
\hline \multicolumn{5}{|c|}{ TGR for the convex metafrontier } \\
\hline EST & 1.0000 & 1.0000 & 1.0000 & 0.0000 \\
\hline LTU & 0.8618 & 0.9924 & 0.9348 & 0.0492 \\
\hline LVA & 0.7286 & 0.8622 & 0.8008 & 0.0546 \\
\hline \multicolumn{5}{|c|}{ TGR for the non-convex metafrontier } \\
\hline EST & 1.0000 & 1.0000 & 1.0000 & 0.0000 \\
\hline LTU & 0.8618 & 0.9924 & 0.9348 & 0.0492 \\
\hline LVA & 0.7286 & 0.8622 & 0.8008 & 0.0546 \\
\hline \multicolumn{5}{|c|}{ Convexity gap } \\
\hline EST & 1.0000 & 1.0000 & 1.0000 & 0.0000 \\
\hline LTU & 1.0000 & 1.0000 & 1.0000 & 0.0000 \\
\hline LVA & 1.0000 & 1.0000 & 1.0000 & 0.0000 \\
\hline
\end{tabular}

Source: designed by the authors.

The dynamics in the TGRs for the convex and non-convex metafrontiers are depicted in Fig. 4. Note that the same figure is used as the two types of the meta-frontier coincide. Obviously, the country-specific frontiers kept approaching the metafrontiers with time for both Latvia and Lithuania. This indicates the presence of convergence in the productivity of labour and capital in the Baltic States. However, this kind of convergence was not equally successful across the countries. Lithuania kept increasing the TGR steadily, whereas Latvia experienced a light decline in 2013-2014. The convergence among the Baltic States can be furthered by investments into new equipment, $R \& D$ and infrastructure, creating new technology or increasing labor productivity (Saulaja et al., 2016; Bilan et al., 2020; Carrillo, 2019).

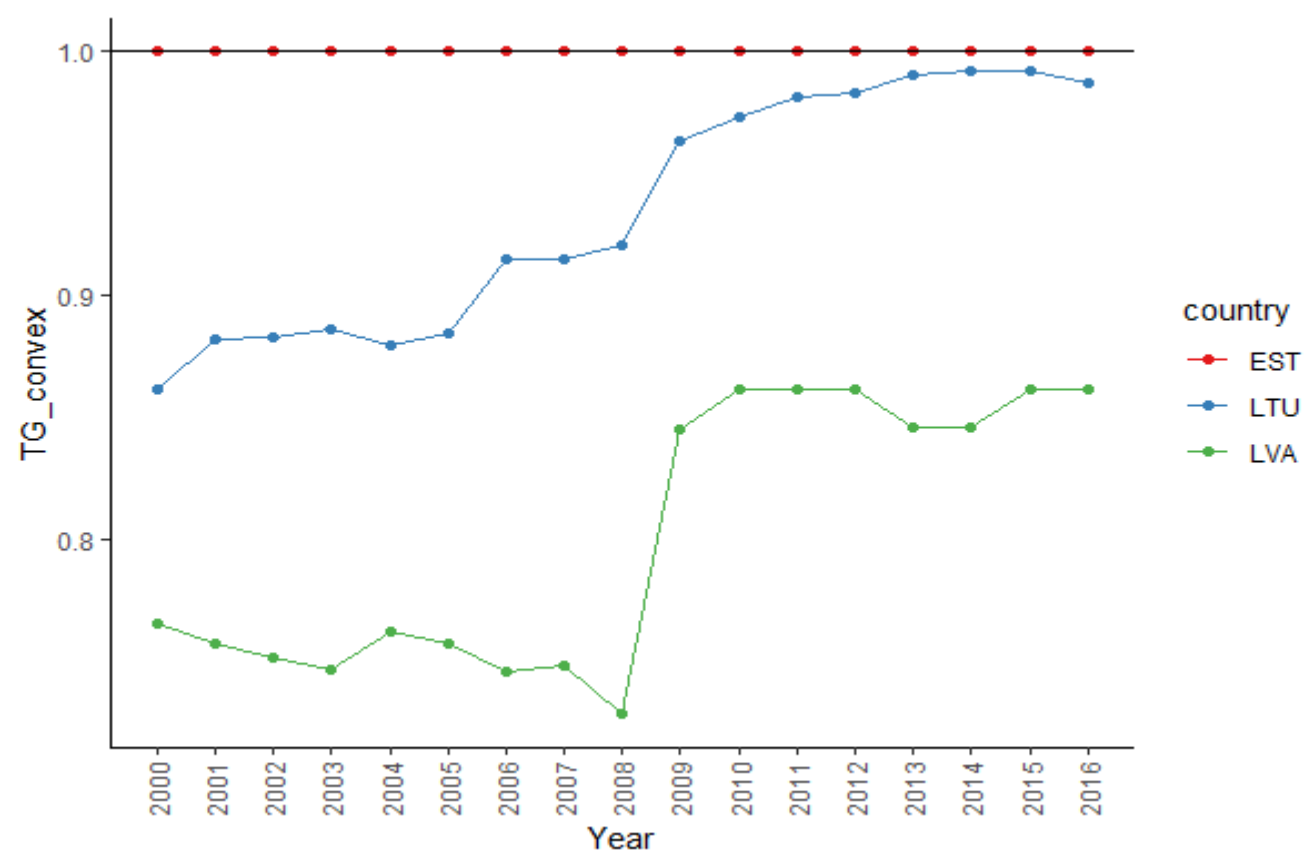

Figure 4. Technology Gap Ratio for the convex and non-convex metafrontiers Source: designed by the authors 
To provide a graphical representation of the underlying production frontiers, the output-input ratios are considered. As we follow the two-inputs-one-output technology, the activity of the countries can be represented by the two ratios - the real value added per labour unit and the real value added per capital unit. These ratios can be termed labour and capital productivity. They can be plotted in the output space thus establishing the output correspondence sets with their boundaries acting the output isoquants (transformation curves). The ratios can be calculated for the observed data and for the ones adjusted for inefficiency. The adjusted data, indeed, are used to construct the output isoquants. The country-specific isoquants can be spanned by a convex hull in order to obtain a representation of the convex meta-technology. Otherwise, the union of the country-specific output correspondence sets is used to obtain the non-convex metafrontier. Practically, this can be achieved by employing the Free Disposal Hull estimator (Deprins et al, 1984).

The convex and non-convex metafrontier in the output space is depicted in Fig. 5. Again, the same figure is used as there are no differences in the two types of the meta-frontier. Several observations can be made from this plot. First, it is obvious that Estonia is the sole country determining the shape of the metafrontier. Second, Lithuania only approaches the metafrontier in the high labour productivity region. The capital productivity is lower for Lithuanian frontier if compared to the Estonian frontier in most cases. Third, the Latvian frontier remains inwards the other frontiers thus indicating underperformance in both directions (i.e., labour and capital productivity).

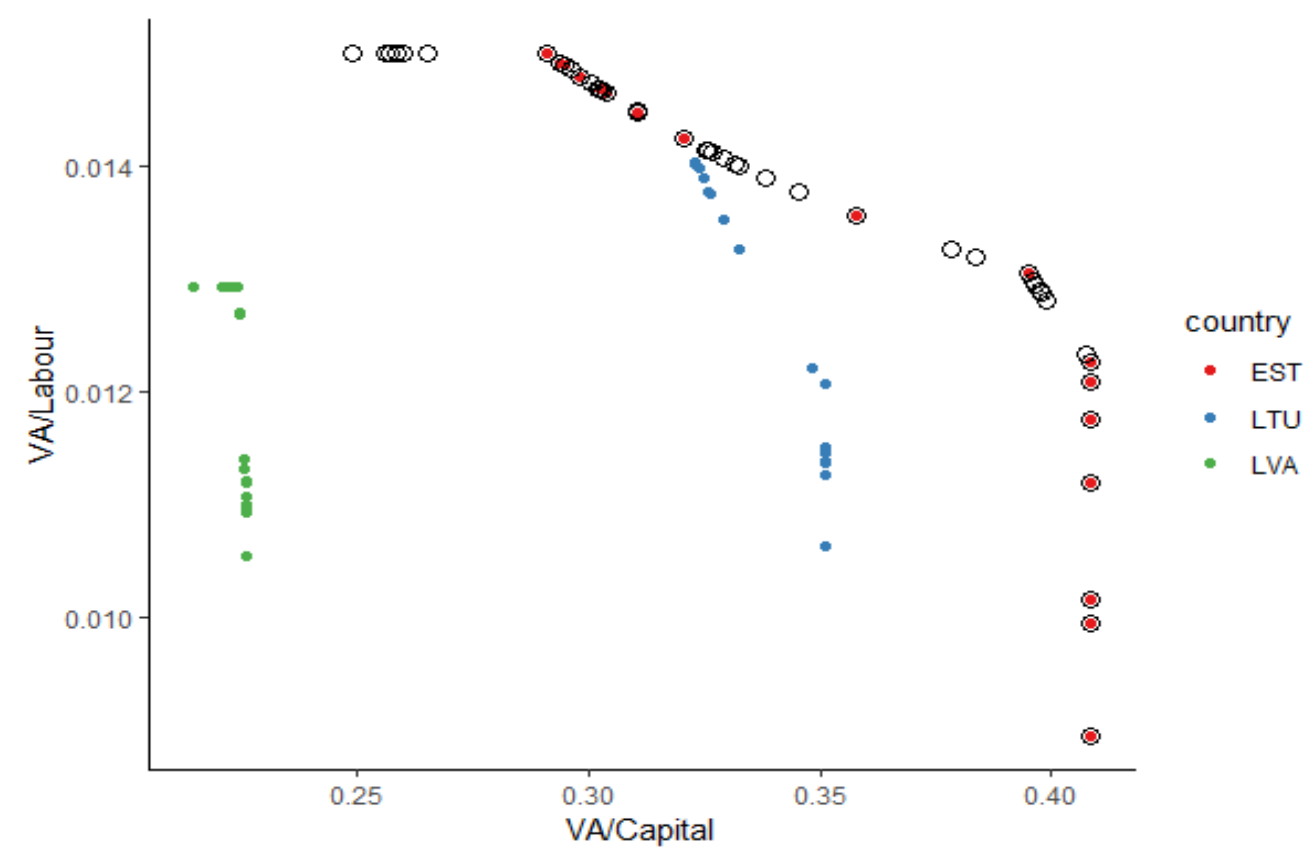

Figure 5. The convex metafrontier and country frontiers

Source: designed by the authors.

To cap it all, Estonia appears as the most efficient country in comparison with Lithuania and Latvia. Estonia shows the highest efficiency scores whether considering the country-specific frontier or the metafrontier. The technology gap ratio analysis also shows the dominance of Estonia's production frontier. The opposite holds for Latvia which demonstrates the lowest performance in all the cases. These results imply that re-allocation of the resources (input factors) should take place by moving towards the high productivity economy in Estonia. 


\section{Conclusion}

This paper established convex and non-convex metafrontiers for the three Baltic States - Estonia, Latvia and Lithuania. The analysis showed that convexity gap did not appear implying no differences between the convex and nonconvex approaches in the case of the three Baltic States. That is due to the fact that Estonia showed rather high productivity and thus defined the Baltic States' metafrontier. Noteworthy, Lithuania also approached the metafrontier, yet had no influence in shaping it. The analysis suggests the high labour productivity is already observed in Lithuania, yet the possibilities for improving capital productivity are still not high enough. In the case of Latvia, both capital and labour productivity needs to be improved in order to approach the metafrontier.

Compared to the country-specific frontiers, Latvia and Lithuania results performed similarly, but the results differed when comparing against the metatechnology. In general, the results suggests Latvian production frontier being inferior to that of Lithuania. Estonian frontier appeared as the best performing one. This indicates the importance of homogenous environment in the productivity analysis. Throughout the time, some shocks due to financial crisis were noticeable for all the countries (relevant to the country-specific frontiers).

Analysis of the multiplier model weights showed that the marginal productivity of inputs varied across countries and time periods. In general, labor input became more important during 2000-2016. This indicates increasing labor productivity in the Baltic States. However, zero weights were obtained in some instances which calls for the use of advanced DEA models with weight restrictions.

Further research can be directed towards measurement of the total factor productivity change and its decomposition. In addition, the measures of efficiency and productivity change could be adjusted for the environmental pressures (e.g. GHG emission) to measure sustainable growth. Finally, different estimation techniques can be applied (e.g. smiparametric models).

\section{References}

Afsharian, M., \& Podinovski, V. V. (2018). A linear programming approach to efficiency evaluation in nonconvex metatechnologies. European Journal of Operational Research, 268(1), 268-280.

Assaf, A., Barros, C. P., \& Josiassen, A. (2010). Hotel efficiency: A bootstrapped metafrontier approach. International Journal of Hospitality Management, 29(3), 468475.

Banker, R. D., Charnes, A., \& Cooper, W. W. (1984). Some models for estimating technical and scale inefficiencies in data envelopment analysis. Management Science, 30(9), 1078-1092.

Beltrán-Esteve, M., Giménez, V., \& Picazo-Tadeo, A. J. (2019). Environmental productivity in the European Union: A global Luenberger-metafrontier approach. Science of The Total Environment, 692, 136-146.

Bilan Y., Mishchuk, H., Roshchyk, I. \& Kmecova I. (2020). Analysis of Intellectual Potential and its Impact on the Social and Economic Development of European Countries. Journal of Competitiveness, 12, 22-38.

Bjurek, H., Hjalmarsson, L., \& Forsund, F.R. (1990). Deterministic Parametric and Nonparametric Estimation of Efficiency in Service Production: A Comparison. Journal of Econometrics, 46, 213-228.

Bogetoft, P., \& Otto, L. (2011). Benchmarking with DEA, SFA, and R. International Series in Operations Research and Management Science, Vol. 157. Springer. 
Bogetoft, P., \& Otto, L. (2018). Benchmarking with DEA and SFA, R package version 0.27. https://cran.r-project.org/web/packages/Benchmarking/Benchmarking.pdf

Çalik, A., Yapici Pehlivan, N., \& Kahraman, C. (2018). An integrated fuzzy AHP/DEA approach for performance evaluation of territorial units in Turkey. Technological and Economic Development of Economy, 24(4), 1280-1302.

Carrillo, M. (2019). Measuring and ranking R\&D performance at the country level. Economics and Sociology, 12(1), 100-114.

Chang, M. C. (2019). Studying the room for improvement in energy intensity by data envelopment analysis under the metafrontier framework. Energy Strategy Reviews, 26, 100398.

Chang, M. C., \& Hu, J. L. (2019). A long-term metafrontier analysis of energy and emission efficiencies between G7 and BRICS. Energy Efficiency, 12(4), 879-893.

Charnes, A., Cooper, W., \& Rhodes, E. (1978). Measuring the efficiency of decision making units. European Journal of Operational Research, 2, 429-444.

Charnes, A., Cooper, W. W., \& Rhodes, E. (1981). Evaluating program and managerial efficiency: an application of data envelopment analysis to program follow through. Management science, 27(6), 668-697.

Chen, L., Huang, Y., Li, M. J., \& Wang, Y. M. (2020). Metafrontier analysis using crossefficiency method for performance evaluation. European Journal of Operational Research, 280(1), 219-229.

Chiu, C. Y., Lin, C. C., \& Yang, C. H. (2019). Technological catching-up between two ASEAN members and China: A metafrontier approach. China Economic Review, 54, $12-25$.

Cooper, W. W., Seiford, L. M., \& Tone, K. (2007). Data Envelopment Analysis: A Comprehensive Text with Models, Applications, References and DEA-Solver Software. Second Edition. Springer.

Daraio, C., \& Simar, L. (2007). Advanced Robust and Nonparametric Methods in Efficiency Analysis: Methodology and Applications (Vol. 4). Springer.

Debreu, G. (1951). The coefficient of resource utilization. Econometrica 19(3): p. 273-292.

Deprins, D., Simar, L., \& Tulkens, H. (1984). Measuring labor inefficiency in post offices. The Performance of Public Enterprises: Concepts and measurements. M. Marchand, P. Pestieau and H. Tulkens (eds.), Amsterdam, North-Holland, 243-267.

Ding, T., Wu, H., Dai, Q., Zhou, Z., \& Tan, C. (2019). Environmental efficiency analysis of urban agglomerations in China: A non-parametric metafrontier approach. Emerging Markets Finance and Trade, 1-16.

Färe, R., \& Primont, D. (1995). Multi-Output Production and Duality: Theory and Applications. Kluwer Academic Publishers, Boston.

Farrell, M. J. (1957). The measurement of technical efficiency. Journal of the Royal Statistical Society, Series A, Vol. 120(3), p. 253-281.

Giraleas, D., Emrouznejad, A., \& Thanassoulis, E. (2012). Selecting between different productivity measurement approaches: An application using EU KLEMS data. https://mpra.ub.uni-muenchen.de/37965/

Huguenin J. M. (2012). Data Envelopment Analysis (DEA): A pedagogical guide for decision makers in the public sector. Institut de hautes études en administration publique.

Jäger, K. (2017). EU KLEMS Growth and Productivity Accounts 2017 release Description of Methodology and General Notes September 2017, Revised July 2018. http://www.euklems.net/TCB/2018/Metholology_EUKLEMS_2017_revised.pdf

Joro, T., \& Korhonen, P. J. (2015). Extension of data envelopment analysis with preference information: Value efficiency. New York: Springer Science + Business Media. 
Karnitis, G., \& Karnitis, E. (2017). Sustainable growth of EU economies and Baltic context: Characteristics and modelling. Journal of International Studies Vol, 10(1).

Kattel, R., \& Raudla, R. (2013). The Baltic Republics and the Crisis of 2008-2011, EuropeAsia Studies, Vol. 65, No. 3, p. 426-449.

Kerstens, K., O’Donnell, C., \& Van de Woestyne, I. (2019). Metatechnology frontier and convexity: A restatement. European Journal of Operational Research, Vol. 275, Issue 2, p. 780-792

Koopmans, T. C. (1951). An analysis of production as an efficient combination of activities. In: Koopmans, T. C. (Ed.) Activity Analysis of Production and Allocation. Cowles Commission for Research in Economics. Monograph No. 13. New York: Wiley, p. 3337.

Kounetas, K., \& Zervopoulos, P. D. (2019). A cross-country evaluation of environmental performance: Is there a convergence-divergence pattern in technology gaps?. European Journal of Operational Research, 273(3), 1136-1148.

Latruffe, L. (2010). Competitiveness, productivity and efficiency in the agricultural and agrifood sectors. OECD Food, Agriculture and Fisheries Working Papers, No. 30, OECD Publishing.

Lin, Y. H., \& Hong, C. F. (2020). Efficiency and effectiveness of airline companies in Taiwan and Mainland China. Asia Pacific Management Review, 25, 13-22.

Liu, J. S., Lu, L. Y. Y., Lu, W. M., \& Lin, B. J. Y. (2013). Data envelopment analysis 19782010: a citation-based literature survey. Omega, 41, 3-15.

Liu, L., Kang, C.H., Yin, Z.Y., \& Liu, Z.Y. (2019). The effects of fiscal and taxation policies on the innovation efficiency of manufacturing enterprises: A comparative study from the perspective of economic regions. Transformations in Business \& Economics, 18(3), 206-228.

Lovell, C. (1993). "Production frontiers and productive efficiency", in Fried, H., Lovell, C., Schmidt, S. (eds). The Measurement of Productive Efficiency: Techniques and Applications, Oxford University Press, New York, p. 3-67.

Ma, G., Li, X., \& Zheng, J. (2019). Efficient allocation of coal de-capacity quota among Chinese provinces: a zero-sum gains data envelopment model. Chinese Journal of Population Resources and Environment, 17(3), 229-240.

O’Donnell, C.J., Rao, D.S.P., \& Battese, G.E. (2008). Metafrontier frameworks for the study of firm-level efficiencies and technology ratios. Empirical Economics, 34, 231-255.

Pastor, J. T., \& Lovell, C. K. (2005). A global Malmquist productivity index. Economics Letters, 88(2), 266-271.

Podinovski, V.V. (2016). Optimal weights in DEA models with weight restrictions. European Journal of Operational Research, 254(3), 916-924.

Ramanathan, R. (2003). An Introduction to Data Envelopment Analysis: A Tool for Performance Measurement. Sage Publications.

Saulaja, I., Zvaigzne, A., \& Mietule, I. (2016). Labour costs and Productivity in Latvia. Economic Science for Rural Development, 42, 150-156.

Shephard, R.W. (1970). Theory of cost and production functions. Princeton, NJ: Princeton University Press.

Stehrer, R., Bykova, A., Jäger, K., Reiter, O., \& Schwarzhappel, M. (2019). Industry level growth and productivity data with special focus on intangible assets, WIIW Statistical Report No. 8.

Thompson, R. G., Langemeier, L. N., Lee, C. T., Lee, E., \& Thrall, R. M. (1990). The role of multiplier bounds in efficiency analysis with application to Kansas farming. Journal of Econometrics, 46(1-2), 93-108. 
Timmer, M. P., Dietzenbacher, E., Los, B., Stehrer, R., \& de Vries, G. J. (2015). An Illustrated User Guide to the World Input-Output Database: the Case of Global Automotive Production. Review of International Economics, 23, 575-605.

Wang, H., Zhou, P., Xie, B. C., \& Zhang, N. (2019). Assessing drivers of CO2 emissions in China's electricity sector: A metafrontier production-theoretical decomposition analysis. European Journal of Operational Research, 275(3), 1096-1107.

Wilson, P. W. (2008). FEAR 1.0: A Software Package for Frontier Efficiency Analysis with R. Socio-Economic Planning Sciences, 42, 247-254.

Zha, J., Yuan, W., Dai, J., Tan, T., \& He, L. (2020). Eco-efficiency, eco-productivity and tourism growth in china: a non-convex metafrontier DEA-based decomposition model. Journal of Sustainable Tourism, 28(5), 663-685.

Zhang, D., Li, M., Ji, X., Wu, J., \& Dong, Y. (2019). Revealing potential of energy-saving behind emission reduction: A DEA-based empirical study. Management of Environmental Quality, 30(4), 714-730. 